\title{
A força de trabalho em saúde no contexto da Reforma Sanitária
}

(*) Consultor da Organização PanAmericana da Saúde (OPAS). Este texto reproduz palestra realizada na Conferência Nacional de Recursos Humanos para a Saúde, Brasnilia, 13 a 17 de outubro de 1986.

\section{Roberto Passos Nogueira*}

\section{INTRODUÇÃO}

Numa hora em que a idéia de reforma sanitária come. ça a se revestir de uma notável densidade política e, a partir da VIII Conferência Nacional de Saúde, define suas linhas em tomo do direito de todos à saú de, convém perguntar como se situa a força de trabalho setorial, diante dos preceitos e das metas preconizadas por esse movimento.

Dispomos, atualmente, de grande quantidade de dados e informaçōes sobre a força de trabalho em saúde no Brasil, como resultado de um esforço de investigação que se deu nos últimos cinco anos. No entanto, considerada no contexto da reforma sanitária, essa força de trabalho não pode se limitar a ser alvo de uma descrição, através dos números referentes a sua disponibilidade e uso, em seus distintos segmentos. Não basta quantificá-la e descrevé-la; devemos, ao contrário, estabelecer um juízo, ou seja, uma avaliação.

Duas formas de avaliação podem ser feitas, nesse particular:

1. de natureza macroeconômica, levando em conta os aspectos de capacidade de geração de emprego e absorção de pessoal recém-formado, dinamismo do setor no conjun to da economia, perspectivas de ex. pansão, etc.;

2 . de natureza política, que consiste em julgar se a dimensão, distribuição, composição intema e utilização da força de trabalho estão consistentes com as linh as e diretrizes da política nacional de saúde.

No contexto da reforma sanitária, a avaliaçāo política deve responder até que ponto aquelas características estão adequadas aos princípios de universalidade, eqüidade e reso. lutividade dos serviços. Nesta perspectiva, mencionaremos seis problemas que nos parecem representar significativos desafios à iniciativa da reforma sanitária. Começaremos a análise, entretanto, pela dimensão econômica, que conduz a uma apreciação bastante positiva, da força de ti... allho em saúde. Em termos simplificados, apresentamos a tes, de que a força de trabalho em saúde vai bem, do pont te vista macroeconómico e mal, do ponto de vista macropolítico, 
embora quanto a este último aspecto tenha registrado algumas melhorias recentes.

\section{AVALIÇÃO DA DINAMICA ECONOMICA}

A força de trabalho em saúde constitui, atualmente, um expressivo contingente de $3 \%$ de todos os trabalhadores brasileiros. Projetada na base da taxa de crescimento de $100 \%$, ocorrida no período $1970-1980$, deve abranger, hoje, no Brasil, cerca de um milhão e oitocentos mil trabalhadores. A metade desse núme ro está composta por profissionais com uma qualificação específica em saúde, isto é, por pro. fissionais de saúde.

Dentro de um leque de 18 categorias típicas, havia, em 1984, um total aproximado de 600 mil empregos de profissionais de saide, dos quais os médicos ocupavam nada menos que 200 mil postos em estabelecimentos de saúde, com e sem in ternação. No caso dos médicos, a capacidade de geração de empregos excedeu a formação: somente nos estabelecimentos de saúde (descontada, portanto, a ocupação autônoma e noutros tipos de estabelecimentos) foram criados, entre 1977 e 1983, 75 mil empregos de médicos e formados 57 mil, no mesmo período, resultando numa relação de 1,3 emprego/médico.

Por outro lado, o setor passou, com relativo sucesso, pela prova da crise sócioeconômica recente, se considerado em sua globalidade. De fato, o nivel de emprego sofreu uma que da sensivel no segmento privado não-lucrativo, mas se elevou bastante no segmento público, do que resulta uma taxa média de crescimento do emprego, em tomo de $7 \%$ ao ano. Nesta década, apenas um pouco mais baixa da que ocorreu na década de 70 .

A composição interna da força de trabalho em saúde foi diversificada pela incorporação de novas categorias como os psicólogos, fonoau diólogos e fisioterapeutas, a par do movimento contínuo de crescimento das especialidades médicas.

Caberia, é claro, uma análise mais detalhada dos as. pectos qualitativos da expansão do emprego e da força de trabalho em saúde, nesse período, que se deu com relativo aviltamento das condições de inserção institucional, como foi denunciado pelas entidades de classe. Embora contra. riando as expectativas dos profissionais organizados - porque tal movimento ocorreu em forma concomitante com um processo de proletarização -, não há dúvidas de que o ritmo de crescimento do emprego demonstra um acentuado dinamismo desse mercado de trabalho. De outra parte, se aparece rem indícios de desemprego e subemprego, eles podem ser considerados "normais" num setor que está sendo 
submetido, progressivamente, a regras capitalistas de funcionamento.

Aumentando, anualmente, mais que a população, economicamente ativa, a força de trabalho em saúde tende, cada vez mais, a participar, em modo expressivo, no total de empregos ofe recidos na economia. É uma tendência que faz parte do fenômeno de terciarizaçāo das atividades econômicas nas sociedades modernas: o emprego, nos setores primários, é decrescente, estável ou, ligeiramente, crescente nos secundários e florescente no terciário. Ademais, os bens e serviços de saúde tendem a constituir uma fatia cada vez maior dos bens e serviços consumidos pela população, tanto em regimes capitalistas como socialistas. $O$ impulso para a expansão da ocupação em saúde é inexorável e permanente. Nos Estados Unidos, para um gasto de $10 \%$ do PIB em saúde, há em tomo de $8 \%$ dos trabalh adores ocupados em funçōes de saúde. Com nossos modestos $4 \%$, alcançamos $3 \%$ da PEA, mas o potencial de crescimento para o futuro é enorme.

A força de trabalho continuará crescendo a taxas ele. vadas, nas próximas décadas. Sobre isto não cabe a menor dúvida, porque trata-se de um fenômeno natural em qualquer economia modema e, como se diz, nós já somos a 8 ? do mundo e o ritmo só não se manterá, se entrarmos numa crise catastrófica.

A dúvida não paira sobre o crescimento da força de trabalho em saude: paira, exatamente, sobre o como. A questão é saber se vamos crescer, obedecendo às forças imprevisíveis do mercado, estimuladas pela intervenção estatal, mas como result ado de uma medicalização in discriminada dos grupos sociais privilegiados; ou se vamos crescer com um mínimo de racionalidade e em observância a critérios de justiça social; por outras palavras, se a expansão da força de trabalho em saú de dar-se-á, cumprindo os requisitos de universalidade e eqüidade explicitados na atual poli. tica de saúde.

A colocação dessas altemativas já nos remete a um outro plano, o da avaliação política.

\section{AVALIAÇÃo POLITICA}

A despeito da extraordinária expansão observada nos últimos anos, a força de trabalho em saúde continua a exi. bir inúmeros problemas em suas dimensðes qualitativas e quantitativas, que são óbices importantes às políticas a serem desenvolvidas, no âmbito da re forma sanitária. Escolhe. mos seis problemas para exemplificar, mas poderiam ser identificados quinze ou trinta, porque são, facilmente, desdobráveis ou conduzem a outros. 
A Organização Mundial da Saúde vem difundindo o conceito de "desequil íbrio em recursos humanos" para denotar situações que dificultam o alcance de determinadas metas da política de saúde e sobre tal tema promoveu, recentemente, uma importante reunião no México. Preferimos, contudo, falar em problemas, pois desequilíbrio (imbalance) é uma noção funcionalista que dá a impressão de ter existido, previamente, uma situação de equilíbio, o que, raramente, é verdade. $\hat{E}$ próprio da natureza das coisas, não o equil íbrio, mas a desigualdade, o conflito, en fim, o que podemos denominar, numa atitu de avaliativa, problemas.

\section{1 - Concentração Geográfica e Institucional}

Há, nitidamente, no Brasil uma concentração geográfica e institucional que conspira contra os princípios de universalidade e descentralização do sistema de saú de.

Em 1980, a região sudeste, que apresentava $43 \%$ da população, acumulava nada menos que $55 \%$ dos médicos. Por sua vez, a região nordeste, com $29 \%$ da população, dispunha de $19 \%$ dos mé dicos.

Quanto ao emprego total, em 1983, 45\% dos profissionais trabalh ando em estabelecimentos de saúde estavam situados nos estados de São Paulo e Rio de Janeiro, enquanto o nordeste de tinha apenas $20 \%$ do conjunto de $800 \mathrm{mil}$ empregos existentes nesse ano.

Essa má-distribuição geográfica dos profissionais de saúde é reforçada pela concentração nas grandes áreas metropolitanas. Hoje, ninguém mais acredita em iniciativas de interiorizar o médico e outros profissionais, isoladamente, da estrutura de serviços, como um todo. Mas os contrastes persistem e clamam por medidas efetivas, não só no aparato de produção de serviços, especialmente o público, como no sistema educacional: re formulação nos componentes de cargos e salários que estimulem a redistribuição geográfica, ex. tensão de serviços, realmente, eficazes às áre as mais carentes, ape feiçoamento e expansão dos custos de residência e pós-graduação, nas regiões fomecedoras de profissionais, etc.

Mais grave ainda, a nosso ver, é o contexto de desigualdade institucional dentro do setor público que, fortemente, contraria a diretriz de descentralização. Por exemplo: em 1984, o nível municipal apresentava somente $16 \%$ do total de empregos de profissionais de saúde, índice, extremamente, desfavorável, se comparado com o nível estadual (45\%) e federal (39\%). Como municipalizar de fato, se não houver uma transferência real de capacidade instalada, daquel as duas esferas, para domínio das municipalidades? Um processo de simples crescimento da capacidade instala- 
da, em nivel municipal, talvez jamais chegue a eliminar essas grandes diferenças com os outros níveis polftico-administrativos. Como municipalizar, apenas, por expansão se em 1982 os estabelecimentos públicos municipais concentravam o núme ro imisório de treze mil leitos, num universo de cento e trinta leitos públicos? E sete mil consultórios em estabelecimentos sem intemação para um total de trinta $e$ cinco mil, no setor público?

Dar, se pode tirar a conclusão que municipalizar será, na reforma sanitária, forçosamente, a síntese de dois movi. mentos:

1. prioridade na manutenção e expansão do nível mu* nicipal de assistência;

2. transfe rência efe tiva da capacidade instalada (recursos humanos mais instalaçōes) para a esfera municipal.

\section{2 - Composição Interna da Força de Trabalho}

Certamente, o principal problema que se encontra numa análise da composição intema da força de trabalho em saúde, no Brasil, é a polarização entre a categoria de maior qualificaçao (mé dicos) e a de menor qualificação (atenden. tes). Mais de $60 \%$ do emprego, entre 18 categorias, são assumidos por médicos e atendentes. Enquanto isso, os enfermeiros compōem $3,6 \%$ do total de empregos em estabeleci. mentos de saúde e os odontólogos permanecem num patamar de $4 \%$, o que bem ilustra a situação deplorável de nosso atendimen to odontológico-institucional.

Quando, apenas, duas categorias somam mais de $60 \%$ do emprego, o que significa falar de trabalho em equipe? Talvez signifique, apenas, reconhecer que a diversificação intema, como consequência de uma divisão técnica do trabalho, não atingiu um ponto em que a presença de outros profissionais tenha peso real e o trabalho, em equipe, permanece ainda um desiderato.

Mas aquela polarização, além de contrariar o lema tão propalado de trabalho em equipe, tem outros efeitos negativos. A proporção exagerada (ce rca de 30\%) de atendentes comprova que existe, paralelamente, uma questão de quali. ficação profissional não resolvida, já que essa categoria, não legitimada, é preparada, empiricamente, ou através de treinamentos precaríssimos. Os baixos níveis de qualificação do atendente constitui o "calcanhar de Aquiles" do processo de desenvolvimento de recursos humanos, especialmente, em nossas instituições públicas. Não se trata de uma questão formal ou restrita aos interesses do próprio profissio$\mathrm{nal}$, pois, a situação tem, seguramente, reflexos sobre a qualidade dos serviços prestados à população. 
Verif ica-se, nos últimos anos, uma tendéncia à queda da proporção de atendentes no total de empregos. De $37 \%$ em 1978 passou a 30\% em 1984. Para esse declínio vem contribuindo, especialmente, o setor privado, mas também, em parte menor, o público, através do uso crescente de auxiliares de enfe magem. Todavia, a presença do atendente é ainda maciça na composição in tema da força de trabalho em saúde.

A política de promoção de atendente a visitador sanitário ou a auxiliar de enfe rmagem carece, ainda, de apoio e mecanismos de ensino supletivo, suficientemente, ágeis, embora seja a única altemativa corre ta, visto que não se pode tole rar a idéia de simples eliminação desses profissionais. A recente lei do exercício de enfermagem, prevendo a promoção de todos atendentes, em dez anos, é indicativa do caminho a ser seguido, mas tem fall as, porque prevê, somente, a ascenção a auxiliar de enfermagem, quando outras alternativas deveriam ser contempladas. Por outro lado, a me ra exigência legal te rá pouco e feito se não se acompanhar do suporte de programas educativos, nas instituições de saú. de, em articulação com o setor formal de ensino.

\section{3 - Escolaridade do Pessoal Auxiliar}

Este problema está associado, parcialmente, ao anterior, mas refere-se, especificamente, aos baixos níveis de es. colaridade formal da força de trabalho em saúde, no seu segmento de profissionais auxiliares. Um indicador dessa situação é o dado revelado pelo censo de 1980: $47 \%$ das categorias auxiliares não dispunham, sequer, da escolaridade mínima preconizada, constitucionalmente, que é o primeiro grau. Para a criação deste quadro de escassa escolaridade, muito contribui a presença numerosa dos atendentes, parteiras, guardas sanitários e outros grupos classificados, usualmente, como de "nivel elementar".

Como dados complementares, vale mencionar que, naquele ano, os profissionais auxiliares, com primeiro e segundo graus completos, alcançavam as proporções de $22,2 \%$ e $20.6 \%$, respectivamente.

$\mathrm{Na}$ década de 70, deu-se uma melhoria nos níveis de escolaridade, o que se obteve, sobretudo, em função da disseminação de altem ativas de cursos e exames suple tivos, de primeiro e segundo graus. Sem dúvida, dar prosseguimento ao uso da via supletiva de educação ge ral, pelo pessoal já en. gajado no me rcado de trabalho é um dos pontos cruciais de uma política de desenvolvimento de recursos humanos, dentro do esforço de reforma sanitária. Embora não seja esta uma obrigaçao formal do setor saúde, há de se estabelecer estímulos e mecanismos de articulação com o setor de ensi- 
no, para que a escolaridade da força de trabalho em saúde se eleve, subst ancialmente.

Não se pode deixar de mencionar que a elevação da escolaridade, concomitante à melhoria das formas de profissionalização, manifestará efeitos muito benéficos no tipo de serviço que a população recebe.

\section{4 - Extensão da Jornada de Trabalho e Múltiplas Ocupações do Pessoal de Nível Superior}

Muitos dos profissionais de qualificação universitária em saúde têm uma jomada de trabalho que ultrapassa 40 horas semanais. Tal jomada pode ser considerada excessiva, em inúme ros casos, como se constata pelos dados censitários de 1980: $33 \%$ de todos os profissionais universitários e $46 \%$ dos médicos trabalhavam mais de 50 horas semanais. Mais ainda: houve uma tendência a aumentar a extensão da jomada, entre 1970 e 1980 , talvez como mecanismo de compensação para perdas salariais e para substituição da ocupação autônoma.

Interpretando esse fenômeno, André Médici afirma que "as dificuldades de estabelecer laços de autonomia e a "desvalorização" do trabalho destes profissionais favoreceram a procura por um maior número de postos de trabalho, para cada profissional" (in: A Força de Trabalho em Saúde dos Anos Setenta: Percalços e Tendências, inédito).

Assim, a tendência a prolongar a jomada de trabalho pode ser vista como mecanismo compensatório ao processo de "proletarização" do médico e de outros profissionais, dando-se através de uma estratégia de subsistência, em que cada um procura acumular e somar o rendimento de diversos postos, com carga de trabalho, extremamente, variável. Pode-se dizer que essa estratégia não implica, necessariamente, no cumprimento da carga de trabalho formal ou contratada, já que, muitas vezes, isto levaria a um total esgotamento fŕsico e mental do profissional. Mas, não há dúvida, o resultado é o aumento da jomada real de trabalho, mesmo que esta não alcance o limite legal contratado.

Essa situação é acompanh ada pela tendência a aumentar a proporção de empregos, em tempo parcial, em detrimento do de tempo integral: de 1976 a 1980, os médicos, em ocupação de tempo parcial em estabelecimentos de saú. de, elevam-se de $75 \%$ a $78 \%$.

Não há que negar, ademais, que a acumulação de múltiplos postos de trabalho prejudica o rendimento dos médicos e de todos os outros profissionais e, em última instân. cia, prejudica a qualidade dos serviços que são capazes de prestar. Este, entretanto, não é apenas um problema de administraçāo de pessoal que se resolva num passe de mági- 
ca com um sonhado plano perfeito de cargos e salários - há uma realidade de dinâmica do me rcado de trabalho que não deve ser negligenciada. As oportunidades variadas, proporcionadas pela demanda pública e privada, fazem com que a dedicação, em tempo integral, possa ser fraudada nas circunstâncias habituais, a não ser que houvesse um reajuste global das relações de trabalho, entre todas instituições públicas e privadas, o que re quereria um planejamento global da inserção, no me rcado de trabalho.

Essa problemática precisa ser discutida, detidamente, com as próprias categorias envolvidas e seus órgãos representativos, mas, em princípio, mantemos a seguinte posição:

1. o tempo integral deve ser aplicado onde for possivel e conveniente, embora somente determinadas instituições ou em certas áreas restritas, ele poderá se converter numa norma, a curto prazo;

2 . em todas outras situações, deve-se procurar contornar as forças adversas do mercado de trabalho, principalmente, as re ferentes ao médico, mediante melhoria nas condições de cargos e salários, mantendo o tempo parcial e adotando métodos de ge rência mais eficazes das relações de trabalho, inclusive com estí. mulos psicológicos para aumentar a dedicação efe tiva do profissional.

\section{5 - Situação da Mulher no Mercado de Trabalho}

A participação das mulheres na força de trabalho em saúde ascende a nada menos que $70 \%$. Daŕ, alguns pesqui. sadores verem a saúde como um campo de emprego, essencialmente, feminino.

$\mathrm{Na}$ verdade essa elevada proporçāo esconde uma desigualdade, em relação ao sexo masculino: as mulheres estão concentradas numas poucas ocupações de nivel superior (ex.: enfermagem e psicologia) e sua presença é, realmente, majoritária, apenas, nas categorias de mais baixa qualificação, seja de saúde (e.g. atendentes), seja naquelas ligadas a serviços gerais (e.g. serventes). Em 1980, o grupo de serviços gerais e administrativos somava $67 \%$ de mulheres.

Evidentemente, é crescente a entrada de pessoas do sexo feminino nos cursos universitários da área de saúde e isto tem provocado o aumento de sua participação na força de trabalho de maior qualificação. Entretanto, pode-se observar que ainda é pequena a proporção de mulheres en. tre os médicos (20\%), e os odontólogos (28\%).

Mas a relativa desvantagem da mulher no mercado de trabalho em saú de não se afere, apenas, por essas medidas de simples percentuais. No caso dos profissionais de nível superior, há outras condições que não podem deixar de ser 
mencionadas. Em forma bastante resumida, pode-se afirmar, pelos dados de que dispomos dos censos recentes, que as mulheres em relação aos homens:

a) exercem com mais freqüência uma única ocupação;

b) têm, proporcionalmente, renda menor;

c) trabalham um núme ro menor de horas seman ais;

d) têm menos oportunidades de trabalho autônomo.

\section{6 - Segmentação do Mercado de Trabalho}

O me rcado de trabalho em saúde tem, como uma de suas características peculiares, o alto grau de segmentação. Isto significa que as condições de compra e venda da força de trabalho são, extremamente, variáveis para um mesmo tipo de qualificação profissional e um mesmo tipo de servi. ço exigido do trabalhador. Por outras palavras, há uma pa. tente desigualdade nas condições de inserção, nesse merca. do: um médico de instituição municipal ou estadual, em geral, ganha bem menos do que seu colega no nivel federal, para trabalhar a mesma quantidade de horas, passa por me. canismos, totalmente, dife rentes de admissão, não dispoe das mesmas chances de promoção e capacitação em serviço, enfim, há uma falta de isonomia.

No sentido acima explicitado, a falt a de isonomia vai além do desnivelamento do montante de salário, numa da. da categoria; a desigualdade resulta do conjunto das condi. ções gerais de inse rção institucional e isto se refere, tam. bém, às empresas privadas, comparadas entre si ou com o setor público. A falta de isonomia deve ser entendida na acepção etimológica de iso + nomos, isto é, faltam regras que se apliquem igual ou, semelh antemente, para contratar a força de trabalho de qualificação idêntica e que se destina a prestar a mesma forma de serviço. Trata-se de regras de ingresso, ascenção, remune ração, etc.

Regras comuns de funcionamento só poderiam advir de duas circun stâncias (que não são, necessariamente, exclu. dentes entre si):

a) uma grande penetração e difusão de relações capitalistas de trabalho num regime competitivo, em que, as empresas ou instituições, disputassem em busca da força de trabalho capacitada, havendo, por outro la. do, uma concorrência de igual intensidade, entre os profissionais que deman dam emprego;

b) um planejamento cent ralizado, pelo menos referente às instituiçoes públicas, que fixasse pautas para es. trutura de cargos e salários e os meios para pô-las em prática.

A isonomia, entendida como nivelamento das condições de vinculação da força de trabalho, num me rcado pla-

Cadernos de Saúde Pública, R.J., 3 (3): 332-342, jul/set, 1987 
nejado e/ou competitivo, está longe de ocomer em nosso país, porque pressupōe condiçð̄es históricas que ainda não foram alcançadas ou que estão sendo implantadas, muito gradualmente. A isonomia é um produto da história, mas não, apenas, da história das forças econômicas no setor saúde ou em qualquer outro - resulta, também, das lutas reivindicatórias dos grupos profissionais organizados (associações, sindicatos, fe de raçōes, etc.) em defesa dos seus interesses e objetivos. $\mathrm{Na}$ medida em que su rge como resultante de conflitos sociais entre empregadores e empregados, o caráter corporativo desse processo é, inevitavelmente, muito saliente, mas não se pode esquecer que, em geral, ele tende a beneficiar o conjun to dos trabalhadores, a mé dio e longo prazos.

De outra parte, a isonomia é sempre um desiderato, uma imagem-objetivo colocada no horizonte, visto que se toma impossível imaginar uma igualdade perfeita e definitiva, na inserção dos diversos profissionais. A própria dinâmica da concorrência capitalista ou a necessidade de obter benefícios crescente, através do planejamento, fazem com que a isonomia não possa ser encarada como um ponto de chegada absoluto.

Contudo, isto não impede que se perceba, claramente, onde ela está ausente e em seu lugar aparecem sinais e sinto. mas de uma enorme desigualdade: o concurso público, ao lado do clientelismo político, como forma de ingresso; as grandes diferenças de regime de contratação; a distinção de tratamento entre os trabalh adores de carteira assinada e os "recibados"; o contraste entre carreiras bem-planejadas e o status quo funcional; e, para não ir muito adiante, as injustiças flagrantes no nível de remuneração de pessoas que exercem funções idènticas.

São esses traços de segmentarismo que ainda conferem, ao mercado de trabalho em saúde, uma fe ição quase pré-capitalista. E, é-se obrigado a reconhecer, o nivelamento, em direção à isonomia, representa uma modemização, no qual um dos motores é a própria luta dos empregados por melhores condições de contratação e trabalho.

Outro móvel da isonomia reside na forma de financiamento dos serviços de saúde. Qu ando o conjunto dos serviços é alimentado por uma fon te comum de custeio, a igualdade de tratamento, em relação aos trabalhadores, tende a se impor, a despeito dos obstáculos legais e administrativos. Isto ocorre ria, numa lipótese pouco realista, se todos os serviços fossem mantidos, por compra direta, pelos usuá. rios, num esquema de livre ofe rta ou, como parece, ser inevitável, no futuro, se todos dependessem de uma única e mesma fonte de natureza pública. Uma das barreiras que se apresentam, hoje, à isonomia, no setor público, está em que 
cada tipo de instituição mantém vínculo de financiamento com uma fonte básica, tal como os tesouros estaduais, mu. nicipais e federal. Os limites de recursos de cada fonte se transformam nos limites à igualdade de tratamento.

Nesse sentido, não cabem dúvidas de que as Ações In. tegradas de Saúde, ao estabelecerem um laço comum de fi. nanciamento pela Previdência Social, têm sido um estímulo efetivo às condições de isonomia, embora seus efeitos ainda sejam bastante modestos e restritos, aos aspectos de remu. ne ração dos médicos. De muito maior alcance será o estabelecimento de fundos unificados nos diversos níveis de governo, conforme proposto pela VIII Conferência Nacional de Saúde, e que passa a ser, desde já, um dos alicerces da reforma sanitária.

A forma de operação desses fundos merece bem maior discussão, mas cremos que serão decisivos na criaç̃o de condições objetivas para a isonomia, de tal modo a com. plementar as condições subjetivas, dadas pela mobilização das categorias in te ressadas. 